\title{
Reply to letter to the editor by J.-M. Kim et al. on "Sexual function and quality of life in women with cervical cancer before radiotherapy: a pilot study" by Grion et al.
}

\author{
R. C. Grion ${ }^{1} \cdot$ Luiz Francisco Baccaro ${ }^{1}$ A. F. Vaz $^{1} \cdot$ L. Costa-Paiva ${ }^{1} \cdot$ \\ D. M. Conde ${ }^{2}$ A. M. Pinto-Neto ${ }^{1}$
}

Received: 15 March 2016/Accepted: 17 March 2016/Published online: 6 April 2016

(c) Springer-Verlag Berlin Heidelberg 2016

We thank you for your letter and acknowledge all comments on our study about sexuality and quality of life in women with cervical cancer [1]. A healthy sexual life contributes to the individual sense of well-being, improves interpersonal relationships and is an important component of the overall quality of life [2]. This is also true in women diagnosed with gynecological cancer. In our study, we found that a significant proportion of women with cervical cancer is sexually active at the beginning of treatment, however, they have significant sexual dysfunction, due to increased stress after the diagnosis or adverse symptoms related to the tumor [1]. The PLISSIT model which consists in four levels of intervention-Permission, Limited Information, Specific Suggestions and Intensive Therapyhas been widely suggested as an intervention to treat sexual dysfunction after cancer [3]. Kim et al. notes that in Korea, programs based on the PLISSIT model have been successfully implemented in women with gynecological cancer $[4,5]$. We praise this initiative, and understand that with the decrease in mortality associated with cervical cancer, not only the physical, but also psychological and sexual aspects have a growing importance. Programs like these could be extended to other countries around the world.

\section{References}

1. Grion RC, Baccaro LF, Vaz AF, Costa-Paiva L, Conde DM, PintoNeto AM (2015) Sexual function and quality of life in women with cervical cancer before radiotherapy: a pilot study. Arch Gynecol Obstet

2. Kingsberg SA, Rezaee RL (2013) Hypoactive sexual desire in women. Menopause 20:1284-1300

3. Perz J (2015) Ussher JM; Australian Cancer and Sexuality Study Team. A randomized trial of a minimal intervention for sexual concerns after cancer: a comparison of self-help and professionally delivered modalities. BMC Cancer 15:629

4. Chun N (2011) Effectiveness of PLISSIT model sexual program on female sexual function for women with gynecologic cancer. J Korean Acad Nurs 41(4):471-480

5. Nho JH (2013) Effect of PLISSIT model sexual health enhancement program for women with gynecologic cancer and their husbands. J Korean Acad Nurs 43(5):681-689
Luiz Francisco Baccaro

baccaro@unicamp.br

1 Department of Gynecology, State University of Campinas (UNICAMP), Rua Alexander Fleming, 101, Cidade Universitária Zeferino Vaz, Campinas 13083-881, SP, Brazil

2 Breast Clinic, Hospital for Maternal and Child Healthcare, Goiania, GO, Brazil 